\title{
Impacts of volatilisation on light scattering and filter-based absorption measurements: a case study
}

\author{
J. Backman ${ }^{1}$, A. Virkkula ${ }^{1}$, T. Petäjä ${ }^{1}$, M. Aurela ${ }^{2}$, A. Frey ${ }^{2}$, and R. Hillamo ${ }^{2}$ \\ ${ }^{1}$ Department of Physics, University of Helsinki, P.O. Box 64, 00014, Finland \\ ${ }^{2}$ Finnish Meteorological Institute, P.O. Box 503, 00101, Helsinki, Finland
}

Received: 19 March 2010 - Published in Atmos. Meas. Tech. Discuss.: 8 April 2010

Revised: 23 August 2010 - Accepted: 24 August 2010 - Published: 6 September 2010

\begin{abstract}
Aerosol light absorption measurements most commonly rely on filter-based techniques. These methods are influenced by light scattering constituents in the aerosol phase deposited on the filters. The coating of soot by non-absorbing constituents changes the mixing state of soot as the aerosol ages and increase light absorption by the aerosol. Most light scattering constituents in a sub-micron aerosol are volatile by their nature due to their chemical composition and can be volatilized by heating the sample air. The initial mixing state is lost but the remaining light absorption by the aerosol should be by non-coated soot alone.

This was studied during a short field campaign with two groups of equipment measuring in parallel for six days in April 2009 at the SMEAR III station in Helsinki. When heated, the light scattering constituents were evaporated thus reducing the single-scattering albedo $\left(\omega_{0}\right)$ of the aerosol by as much as 0.4. An oven was set to scan different temperatures which revealed the volatility of the urban aerosol at different temperatures as well as the single-scattering albedo's dependence on the non-volatile volume fraction remaining (NVFR). The NVFR was $0.72 \pm 0.13,0.42 \pm 0.06$ and $0.22 \pm 0.05$ at 50,150 and $280^{\circ} \mathrm{C}$ respectively. $\omega_{0}$ behaved analogically, it was $0.71 \pm 0.05,0.62 \pm 0.06$ and $0.42 \pm 0.07$ at the respective temperatures. We found that absorption coefficients measured at different temperatures showed a temperature dependency possibly indicating initially different mixing states of the non-volatile constituents.

By heating the aerosol the mode of the size distribution gets shifted to smaller sizes which in turn changes the filterbased instrument's response due increased penetration depth into the filter by the smaller residual particles. This was compensated for by using size distribution data.
\end{abstract}

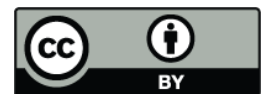

Correspondence to: J. Backman (john.backman@helsinki.fi)

\section{Introduction}

Aerosol particles have a direct influence on the climate because they scatter (Cabada et al., 2004) and absorb (Jacobson, 2001) light and they have the ability to indirectly influence the climate when acting as a cloud condensation nuclei (Ramanathan et al., 2001; Rosenfeld et al., 2008). Light absorbing black carbon (BC) aerosols heat the atmosphere and they may be the second most important component of global warming in terms of direct forcing (Jacobson, 2001; Ramanathan and Carmichael, 2008). BC is the most effective and dominant absorber of visible solar radiation in the atmosphere (Petzold and Schönlinner, 2004; Ramanathan and Carmichael, 2008). The internally mixed state of BC with aerosol constituents can enhance forcing by a factor of two (Jacobson, 2001). BC emissions are mainly anthropogenic in origin. The highest $\mathrm{BC}$ emissions are in the tropics where the incoming solar radiation is the strongest (Ramanathan and Carmichael, 2008).

Soot is externally mixed when it is introduced into the atmosphere, but during transport, the soot particles coagulate with other particles or get coated with sulphates, nitrates or organic species by condensation (Saathoff et al., 2003; Zhang et al., 2008). This results in different mixing states of soot as the aerosol age which in turn increases light absorption from externally mixed to internally mixed (Fuller et al., 1999). Absorption of light in aerosols has been studied for a long time but there are still uncertainties which affect the accuracy of climate models (Bond and Bergstrom, 2006).

The most commonly used filter-based measurement techniques for determining absorption of light in an aerosol are influenced by light scattering aerosols (e.g. Bond et al., 1999; Virkkula et al., 2005). Volatile compounds such as sulphates, nitrates and most of the organic species are evaporated at temperatures around $300{ }^{\circ} \mathrm{C}$ (Engler et al., 2007; Tiitta et al., 2009). At these temperatures BC is still non-volatile (Wehner

Published by Copernicus Publications on behalf of the European Geosciences Union. 
et al., 2005). The residual particles at this temperature consist of soot, crustal material or sea salt. Excluding these compounds, the light scattering constituents in the aerosol phase are volatile. Thus, the disturbance due to the light scattering material to absorption can be reduced by heating the sample air. In practice this can be done by letting the sample air pass through a thermodenuder (Wehner et al., 2002). The amount of evaporated material from the aerosol phase depends on the composition of the particles and is also a function of the time the sample air spends inside the thermodenuder as well as the temperature it is heated to (An et al., 2007; Riipinen et al., 2010)

Filter-based methods for measuring light absorption are sensitive to how deeply the particles penetrate the filter until they are deposited (Arnott et al., 2005; Moteki et al., 2010). By evaporating volatile constituents from the aerosol phase the particles shrink in size. Filter penetration among other things is a function of size (VanOsdell et al., 1990) and thus, by heating and shifting the mode of the size distribution towards smaller sizes we alter the penetration of the particles. This increases the instrument's response to light absorbing particles deposited on the filter.

It has also been shown that the coating of absorbing aerosol particles with non-absorbing shells increase the mass absorption cross section (MAC) of soot which in turn leads to an over prediction of BC concentrations (Fuller et al., 1999). By heating the sample air the initial mixing state of the aerosol is lost. This reduces the uncertainties of over-prediction of $\mathrm{BC}$ concentrations due to different mixing states soot in the aerosol.

It is known that externally mixed soot collapses into globules as the particles age in the atmosphere during cloud processing (Mikhailov et al., 2006). In the laboratory study by Slowik et al. (2007) it was shown that the collapse of the fractal state of soot depends on the coating thickness of the liquid causing the collapse the particles. After denuding they found some rearrangement towards a fractal state. However, the effect on cloud processed atmospheric aerosol consisting of a vast variety of different volatile inorganic and organic species is unknown.

In this study a suite of optical instruments was deployed to the station for measuring ecosystem-atmosphere relations III (SMEAR III) (Järvi et al., 2009) in Helsinki to measure the optical properties of urban background aerosol with and without a volatilisation oven in front of the instruments for a short field campaign (Backman, 2009). Absorption after the volatilisation was measured with a Particle Soot Absorption Photometer (PSAP) along with a nephelometer and size distribution measurements. They were compared with non-heated aethalometer, nephelometer, and size distribution measurements along with measured elemental and organic carbon content of the ambient particle population.

The aim was to study whether the performance of filterbased methods can be improved with the aid of volatility analysis, in which the compounds responsible for scattering

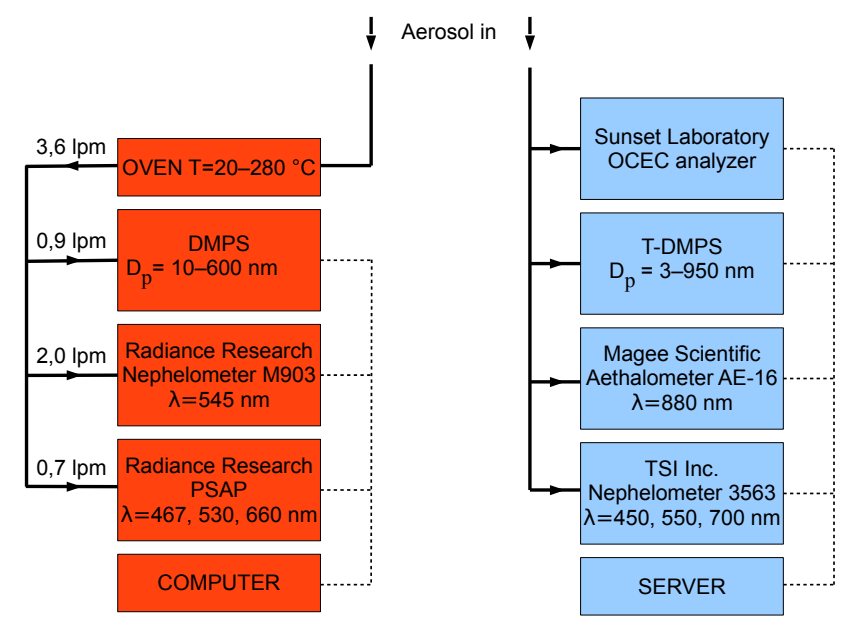

Fig. 1. The system setup used during the short field campaign at the SMEAR III station.

are progressively evaporated from the aerosol sample. Until recently, there was no quantitative method for compensating for the effect of the depth of particle penetration in to the filter. For particles smaller than $200 \mathrm{~nm}$, which is expected after a thermodenuder, the effect of increased instrument response gets significant (Nakayama et al., 2010). The aim is also to estimate the effect of shrinking and subsequent increase of particle penetration depth with the method of Nakayama et al. (2010) .

\section{Experimental setup}

A schematic illustration of the instrument setup is presented in Fig. 1.

The devices with a non-heated sampling line are refered as "non-heated" and "cool" and are measuring at SMEAR III continuously (Järvi et al., 2009). The instruments operated with the thermodenuder are hereafter refered to as "heated".

The campaign instruments were taking the sample through a Minnesota $\mathrm{PM}_{10}$ inlet approximately three meters from the SMEAR III standard instruments. Prior to the field campaign the operation of the instruments was verified in the laboratory.

The instruments after the thermodenuder (also referred to as oven) were operated at the SMEAR III station for six days between 9-14 April 2009 with a constant $280^{\circ} \mathrm{C}$ oven temperature. During the following $23 \mathrm{~h}$ period the oven temperature was varied in three steps $\left(50,150\right.$ and $\left.280^{\circ} \mathrm{C}\right)$. A single temperature scan was completed in approximately $2.5 \mathrm{~h}$. A more thorough description of the instruments is given in the following sections. 


\subsection{SMEAR III instrumentation (non-heated)}

The optical properties with a non-heated inlet were measured using a scatter/backscatter integrating nephelometer TSI Inc. 3653 (St. Paul, MN, USA) which measures at 450, 550 and $700 \mathrm{~nm}$ wavelengths (Anderson et al., 1996). The instrument does a geometrical integration of the scattered intensity with a Lambertian light source and an orthogonally orientated detector. The design of the TSI Inc. 3653 allows measurements of backscattering and total scattering by aerosols but only total scattering coefficients were used in this study. The data used had a time resolution of one minute.

Light absorption coefficients were calculated from a Magee Scientific Aethalometer AE-16 (Berkeley, CA, USA) measuring at a wavelength of $880 \mathrm{~nm}$ (Hansen et al., 1984; Arnott et al., 2005). This instrument uses a filter-based optical method for estimating the $\mathrm{BC}$ concentration which can be used to calculate absorption coefficients (Arnott et al., 2005). This instrument had a time resolution of five minutes.

The ambient particle number size distribution between 3 to $950 \mathrm{~nm}$ was measured with a Twin-Differential Mobility Particle Sizer (TDMPS, Aalto et al., 2001). The TDMPS consisted of two Hauke-type (Winklmayr et al., 1991) differential mobility analyzers (DMA) with closed loops for the sheath air flows (Jokinen, 1995) connected to a Condensation Particle Counter (CPC). The first DMPS system measured from 3-50 nm with a TSI 3025 CPC, (Stolzenburg and McMurry, 1991) and the second from 10 to $950 \mathrm{~nm}$ with a TSI 3010 CPC, (Mertes et al., 1995). A full number size distribution from 3 to $950 \mathrm{~nm}$ was obtained with a ten minute time resolution.

Elemental carbon (EC) and Organic Carbon (OC) mass concentrations were measured with a Sunset Laboratory OCEC M3F (Tigard, OR, USA) via thermal-optical analysis (Birch and Cary, 1996). This is done by depositing particles on a quartz filter by heating the sample subsequently in two different atmospheres (helium and helium plus oxygen). In the pure $\mathrm{He}$ atmosphere the sample is heated in steps to evolve the collected OC via pyrolysis, thus making the filter darker while monitoring the filter transmittance. In the next step the oven is cooled and EC and the pyrolysed OC is exposed to $\mathrm{He}-\mathrm{O}_{2}$ mixture. From the detected combustion products the amount of OC and EC can be determined. The amount of EC is determined after the filter transmittance returns to its initial value. The OCEC analyzer had a time resolution of one hour.

\subsection{Campaign instrumentation (heated)}

An oven was used to evaporate the volatile constituents from the aerosol. It consisted of a stainless steel tube surrounded by a heating cable. The oven temperature was controlled with a computer through a Drew Scientific 5310 proportionalintegral-derivative (PID) controller. The time resolution in scanning the temperatures was poor due to large thermal mass of the oven incorporated with insufficient cooling. Thus the oven was operated at a constant $280^{\circ} \mathrm{C}$ temperature for the beginning of the campaign and a short test of varying the temperature was conducted at the end of the campaign. During the laboratory measurements the residence time in the oven was $1.2 \mathrm{~s}$ and during the campaign $1.0 \mathrm{~s}$. Although this is not long enough to fully evaporate all of the volatile material from the aerosol phase (Riipinen et al., 2010), it is still much longer than e.g. $0.3 \mathrm{~s}$ residence time used in some earlier studies (e.g., Philippin et al., 2004).

Light scattering of the heated sample was measured with an integrating nephelometer (Radiance Research Inc., Seattle, WA, USA) M903 that measured total light scattering coefficients at a wavelength of $545 \mathrm{~nm}$ (Liu et al., 2002; Heintzenberg et al., 2006). The absorption coefficients were determined with a three wavelength Particle Soot Absorption Photometer (PSAP, Radiance Research Inc., Seattle, WA, USA) measuring at 467, 530 and $660 \mathrm{~nm}$ (Virkkula et al., 2005).

Aerosol number size distributions after heating were measured with a DMPS at particle sizes from 10 to $600 \mathrm{~nm}$ (Hoppel, 1978; Aalto et al., 2001). The DMPS consisted of a $28 \mathrm{~cm}$ Hauke-type DMA (Winklmayr et al., 1991) with closed loop flow arrangements (Jokinen, 1995) and a TSI Inc. 3010 CPC (Mertes et al., 1995) for particle counting. In this system sample and sheath air flows were set to 0.9 and $7.41 \mathrm{~min}^{-1}$. The time resolution was $10 \mathrm{~min}$.

For comparison between the campaign instruments and the SMEAR III instruments, the oven was switched off at the end of the campaign period. This enabled us to verify the performance of the campaign devices.

\subsection{Data processing}

Both the PSAP and the Aethalometer use a filter-based method for measuring light absorption by attenuation of light transmitted through a filter matrix while particulate matter is collected onto the filter resulting in a reduction in the light transmission. An uncorrected absorption coefficient is obtained from

$\sigma_{0}=\frac{A}{V} \ln \left(\frac{I_{t-\Delta t}}{I_{t}}\right)$

where $A$ is the area of the sample spot, $V$ is the volume of the air that passes the filter in the time $\Delta t . I_{t-\Delta t}$ and $I_{t}$ are the light transmission through the filter before and after the time $\Delta t$ has elapsed. This relationship, however, changes as the filter gets loaded with both light absorbing and light scattering aerosol particles. Procedures for correcting for various effects are presented in Bond et al. (1999); Weingartner et al. (2003); Arnott et al. (2005), and in Virkkula et al. (2005). The light scattering aerosol deposited in the filter gets wrongly interpreted as absorption, if not taken into account. 
Generally, the absorption coefficient $\sigma_{\mathrm{AP}}$ may be calculated from

$\sigma_{\mathrm{AP}}=f \sigma_{0}-s \sigma_{\mathrm{SP}}$

where $f$ is a correction factor that depends on both the amount and also on the darkness of the deposited aerosol material. $\sigma_{\mathrm{SP}}$ is the scattering coefficient and $s$ is the fraction of scattering that is interpreted as absorption. In order to correct for this also $\sigma_{\mathrm{SP}}$ has to be measured, preferably at the same wavelength as $\sigma_{0}$ was measured at. If the two parameters are measured at different wavelengths $\lambda_{1}$ and $\lambda_{2}$, either of them has to be interpolated or extrapolated to the matching wavelength with the aid of the Ångström exponent

$\alpha_{12}=-\frac{\log \left(\sigma_{1} / \sigma_{2}\right)}{\log \left(\lambda_{1} / \lambda_{2}\right)}$,

which describes the wavelength dependency of scattering or absorption. The Ångström exponent can be used to relate the data to the same wavelength $\left(\lambda_{x}\right)$ with

$\sigma_{x}=\sigma_{1}\left(\frac{\lambda_{1}}{\lambda_{x}}\right)^{\alpha_{12}}$.

This requires the assumption that the spectral dependence of the Ångström exponent is constant.

By using Eqs. (3 and 4), the coefficients can be interpolated or extrapolated to a arbitrary wavelength if they were measured at different wavelengths. In this study, the PSAP light absorption coefficient data were interpolated using this method to the same wavelength as the M903 nephelometer measured at. The TSI nephelometer light scattering coefficient data were extrapolated to the same wavelength as the Aethalometer measured at $(880 \mathrm{~nm})$.

The ratio of scattered light to light extinction by particles is called single-scattering albedo, defined as

$\omega_{0}(\lambda)=\frac{\sigma_{\mathrm{SP}}(\lambda)}{\sigma_{\mathrm{SP}}(\lambda)+\sigma_{\mathrm{AP}}(\lambda)}=\frac{\sigma_{\mathrm{SP}}(\lambda)}{\sigma_{\mathrm{ext}}(\lambda)}$.

The $\omega_{0}$ depends on the aerosol size distribution and on the chemical composition and it is wavelength dependent. It is the key parameter governing the amount of cooling or heating an atmospheric aerosol layer can induce (Seinfeld and Pandis, 2006).

\subsubsection{PSAP data}

The method used in this study for compensating for the PSAP transmittance decrease and for scattering aerosols is described by Virkkula et al. (2005) and by Virkkula (2010). It is an iterative method which takes the darkness of the aerosol deposited on the filter into account. Initially $\omega_{0}$ is calculated from the raw count data produced by the PSAP and $\sigma_{\mathrm{AP}}$ was calculated using an iterative procedure

$\sigma_{\mathrm{AP}}=\left(k_{0}+k_{1}\left(h_{0}+h_{1} \omega_{0}\right) \ln (\mathrm{Tr})\right) \sigma_{\mathrm{AP}}-\mathrm{s} \sigma_{\mathrm{SP}}$
Table 1. Values used in Eq. (6) to calculate the light absorption coefficients with the iterative method described by Virkkula et al. (2005). The coefficients are from Virkkula (2010).

\begin{tabular}{ccccc}
\hline$k_{0}$ & $k_{1}$ & $h_{0}$ & $h_{1}$ & $\mathrm{~s}$ \\
\hline 0.358 & -0.640 & 1.17 & -0.71 & 0.017 \\
\hline
\end{tabular}

where the factors $k_{0}, k_{1}, h_{0}, h_{1}$, and $s$ are the constants presented in Table 1 and $\operatorname{Tr}$ is the filter transmittance. A limit for convergence was set to $0.01 \mathrm{Mm}^{-1}$, which was typically achieved after 2-3 cycles. The values of the coefficients used here were calculated for $530 \mathrm{~nm}$ but were used for absorption coefficients calculated at $545 \mathrm{~nm}$. This inconsistency is thought to be negligible or minor and was not further investigated.

This method was also compared with the more commonly used method that is described by Bond et al. (1999) and by Ogren (2010) denoted $\sigma_{\mathrm{AP}, \mathrm{O} 10}$

$\sigma_{\mathrm{AP}, \mathrm{O} 10}=\frac{\sigma_{0}}{1.5557 \mathrm{Tr}+1.0227}-0.0164 \sigma_{\mathrm{SP}}$

as derived by Virkkula (2010). This is partly the method the PSAP's firmware uses to calculate the absorption coefficients displayed on the front display of the instrument and reported through the serial port. The last term of Eq. (7) corrects for the scattering aerosol deposited on the filter.

Since the Radiance Research M903 is a one wavelength nephelometer, the light absorption coefficients were interpolated to $545 \mathrm{~nm}$ using the Ångström exponents calculated between 530 and $660 \mathrm{~nm}$ using Eqs. (3 and 4). At $545 \mathrm{~nm}$ the correction for light scattering aerosols was done using Eqs. (6 and 7).

Further the PSAP data were corrected for the penetration depth dependency on instrument response which was parametrized by Nakayama et al. (2010). Penetration depth in fibre-filters used in a PSAP is a function of face velocity and particle size (VanOsdell et al., 1990). The face velocity of the particles were found to be of less importance for flow rates of between 0.3 and $0.71 \mathrm{~min}^{-1}$ than particle size in the study by Nakayama et al. (2010). The airflow trough the PSAP during the campaign was around $0.71 \mathrm{~min}^{-1}$. The size dependent over-prediction factor caused by increased filter penetration by smaller particles was calculated using

$F\left(D_{\mathrm{p}}\right)=0.590+148.3 / D_{\mathrm{p}}$

From the size distribution data on the residual aerosol measured by the DMPS a mass-weighted correction factor was calculated using

$F($ ave $)=\frac{\int \mathrm{F}\left(\mathrm{D}_{\mathrm{p}}\right)\left(\mathrm{dM} / \mathrm{d} \log \mathrm{D}_{\mathrm{p}}\right) \mathrm{d} \log \mathrm{D}_{\mathrm{p}}}{\int\left(\mathrm{dM} / \mathrm{d} \log \mathrm{D}_{\mathrm{p}}\right) \mathrm{d} \log \mathrm{D}_{\mathrm{p}}}$

as suggested by Nakayama et al. (2010). 
The parametrisation was done for particle sizes between 100 and $600 \mathrm{~nm}$. Due to diffusion even smaller particles are likely to penetrate less into the filter in contrary to the parametrisation (Eq. 8) when continued to particle sizes smaller than $100 \mathrm{~nm}$ used in the mass weighted correction factor in Eq. (9). This is supported by the fractional penetration for the Pall E70/2075W filter (used in the PSAP) determined by VanOsdell et al. (1990).

\subsubsection{Aethalometer data}

The Aethalometer estimates black carbon mass concentrations by measuring the change in the attenuation of light through a fibre filter. From these data, the light absorption coefficients can be calculated for example using the algorithms presented in Arnott et al. (2005) or in Weingartner et al. (2003). In this study the algorithm as described in Arnott et al. (2005) was used to convert the mass concentration values to absorption coefficients using

$\sigma_{\mathrm{AP}, n}=\frac{\mathrm{SGBC}_{n}-\alpha \sigma_{\mathrm{SP}, n}}{M} \sqrt{1+\frac{\frac{\mathrm{Vdt}}{A} \sum_{i=1}^{n-1} \sigma_{\mathrm{AP}, i}}{\tau_{a, \mathrm{fx}}}}$,

which is a semi-empirical method with the calibration function derived from a basic two-layer model. SG is the MAC factory value used by the instrument. The factors $\alpha, \tau_{a, \mathrm{fx}}$ and $M$ are empirical values for scattering offset, filter absorption optical depth were the particles are embedded and multiple scattering enhancement factor respectively. The filter absorption optical depth $\tau_{a, \text { fx }}$ is directly dependent on particle penetration depth into the filter. Sub-index $\mathrm{n}$ is the $n$th value since filter change. The values used in Eq. (10) are presented in Table 2 . The values $M$ and $\tau_{a, \text { fx }}$ were calculated assuming the same wavelength dependency for the coefficients as presented in Arnott et al. (2005) using the more suitable values of $M=3.688$ and $\tau_{a, \mathrm{fx}}=0.2338$ for ambient measurements at a wavelength of $521 \mathrm{~nm}$.

Equation (10) requires that the light scattering coefficients $\sigma_{\mathrm{SP}}$ are determined at the same wavelength at which the $\mathrm{BC}$ concentrations were measured. The AE-16 aethalometer measures at a wavelength of $880 \mathrm{~nm}$ so the light scattering coefficients were extrapolated to the same wavelength using Eqs. (3 and 4). The extrapolation was done from the Ångström exponents calculated between 550 and 700 nm from the TSI nephelometer data.

\section{Results and discussion}

\subsection{Verification experiments}

Evaporation of volatile material from the particle phase in an oven is a function of the time the aerosol resides in the thermodenuder (An et al., 2007; Riipinen et al., 2010). Prior to utilizing the oven in the field we tested it with laboratory-generated ammonium sulphate $\left(\left(\mathrm{NH}_{4}\right)_{2} \mathrm{SO}_{4}\right)$ and
Table 2. Values used in Eq. (10) to calculate the light absorption coefficients from optical BC measurements with a AE-16 aethalometer. $\alpha, M$ and $\tau_{a, \mathrm{fx}}$ are empirical values.

\begin{tabular}{ccccc}
\hline Wavelength $(\mathrm{nm})$ & $\mathrm{SG}\left(\mathrm{m}^{2} \mathrm{~g}^{-1}\right)$ & $100 \alpha$ & $M$ & $\tau_{a, \mathrm{fx}}$ \\
\hline 880 & 16.62 & 10.38 & 4.05504 & 0.15747 \\
\hline
\end{tabular}

sodium chloride $(\mathrm{NaCl})$ aerosol. These aerosols were produced with two different nebulizers. The salts were dissolved in deionized water. The humid aerosol was then dried with a silica gel diffusion dryer before it was led in to the oven.

The residence time of the aerosol in the oven was $1.2 \mathrm{~s}$ with a flow of $3.01 \mathrm{~min}^{-1}$. With this flow rate the volatilisation of ammonium sulphate was complete while most of the sodium chloride did not evaporate (Fig. 2). The temperature where $50 \%$ of the ammonium sulphate aerosol volume was evaporated was $145^{\circ} \mathrm{C}$. The $50 \%$ value in terms of particle number occurred already at $130{ }^{\circ} \mathrm{C}$. At $200^{\circ} \mathrm{C}$ only $10 \%$ of the volume and $1 \%$ of the particle number survived the oven. This implies that as volatile species as ammonium sulphate are sufficiently evaporated in the oven at $280{ }^{\circ} \mathrm{C}$. The fact that the volume fraction remaining drops slower (Fig. 2a) than the amount of particles remaining (Fig. 2b) indicates that the remaining volume fraction is a function of the initial size of the particles. For semi-volatile species and lower temperatures we are more likely to measure the rate of evaporation rather than equilibrium conditions as is commonly the case for thermodenuder applications (Riipinen et al., 2010). The sodium chloride aerosol volume decreased to $80 \%$ at $300^{\circ} \mathrm{C}$. This may be an indication of impurities in the nebulizer or a non-constant particle production rate which is the more probable reason for the observed behaviour. Otherwise the thermodenuder did not affect remarkably the volume or number concentration of the sodium chloride particles.

Before deploying the campaign instruments to the SMEAR III station, the PSAP and the Nephelometer M903 were tested in the laboratory. The flow of the PSAP instrument was calibrated with the least squares method curve fitting with a slope of $1.002 \pm 0.009$ and an offset of $0.017 \pm 0.010$. The uncorrected absorption $\left(\sigma_{0}\right)$ determined with the PSAP were corrected accordingly.

The noise of the PSAP was estimated to be less than $0.65 \mathrm{Mm}^{-1}$ with the formula $\delta \sigma_{\mathrm{AP}}=10^{0.60-1.31 \log (\Delta t)}$ as in Springston and Sedlacek (2007) with an averaging time $\Delta t$ of $4 \mathrm{~s}$. The noise of the PSAP was later measured to be less that $0.48 \mathrm{Mm}^{-1}$ while sampling particle free and 1 -second data.

The Radiance Research Nephelometer M903 was calibrated using carbon dioxide and particle free air. The noise of the nephelometer was then determined to be less than $0.17 \mathrm{Mm}^{-1}$ with flow rates between one and three litres per minute and 0.5 -second data. 

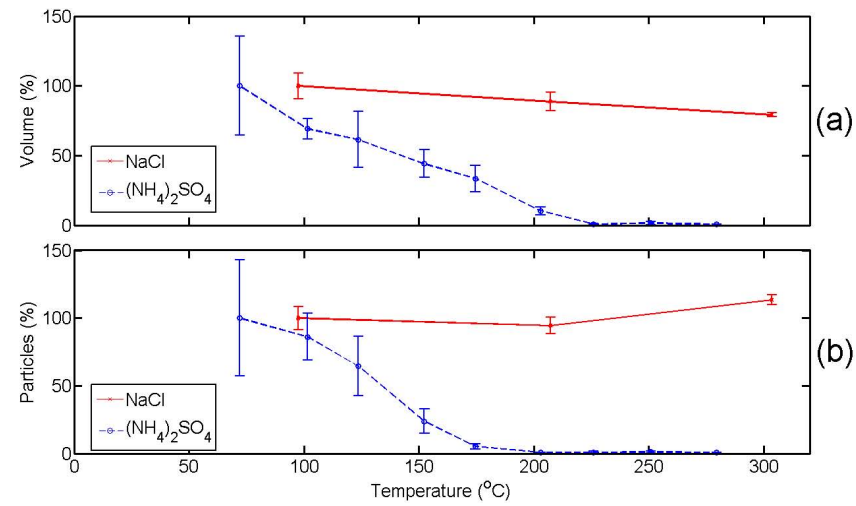

Fig. 2. The volume (a) and particle number (b) fractions left after the laboratory generated aerosol had been heated to different temperatures. The error bars are the standard deviation of the calculated values for a certain temperature.

\subsection{Volatility of urban aerosol}

Optical properties, OC and EC mass concentration at SMEAR III station in Finland were monitored from 9 April to 15 April 2009. The experiments were conducted in parallel with the thermodenuder at an elevated temperature and without heating (Fig. 1). At the start of the field campaign the oven was kept at a constant temperature of $280^{\circ} \mathrm{C}$ from 9 April LT 11:00 to 14 April LT 10:00. During the last $23 \mathrm{~h}$ period of the experiments, from 14 April LT 10:00 to 15 April LT 09:00, the oven temperature was scanned from $50^{\circ} \mathrm{C}$ to $280^{\circ} \mathrm{C}$. First we discuss the results at the constant oven temperature and subsequently present the findings with the variable oven temperature, which progressively evaporates volatile material from the particulate phase.

\subsubsection{Constant oven temperature}

The time series of optical and physical parameters measured during the campaign are presented in Figs. 3 and 4.

The heated and cool coefficients $\sigma_{\mathrm{SP}}$ and $\sigma_{\mathrm{AP}}$, as well as the simultaneously measured $\mathrm{OC}$ and EC concentrations are plotted in Fig. 3. The cool scattering coefficient $\left(\sigma_{\mathrm{SP}, \mathrm{TSI}}\right)$ followed closely the OC variations, the heated $\left(\sigma_{\mathrm{SP}, \mathrm{M} 903}\right)$ not as well. It is very obvious already from this time series that most of the scattering material is volatile at $280^{\circ} \mathrm{C}$. Both absorption measurements track the EC concentrations and each other, as they should. The difference between the heated and cool $\sigma_{\mathrm{AP}}\left(\sigma_{\mathrm{AP}, \mathrm{PSAP}}\right.$ and $\left.\sigma_{\mathrm{AP}, \mathrm{AETH}}\right)$ is mainly due to the different wavelengths although there are some periods with high noise of $\sigma_{\mathrm{AP}, \mathrm{PSAP}}$, for instance on the afternoons of 10 April, 11 April, 12 April and 13 April whereas $\sigma_{\mathrm{AP}, \mathrm{AETH}}$ was much more stable in these periods. The data do not give a clear and unambiguous explanation to these. In principle one explanation could be that the instrument became noisy after the light transmittance through the filter had decreased to a low

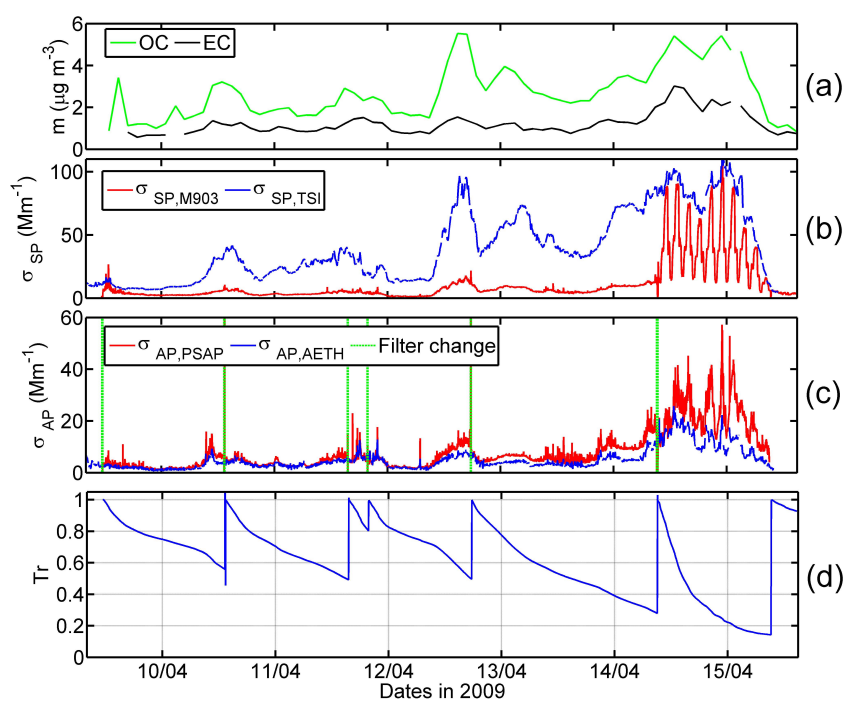

Fig. 3. The values in the figure are (a) organic carbon (OC), elemental carbon (EC), (b) $\sigma_{\mathrm{SP}, \mathrm{M} 903}$ (heated) at $545 \mathrm{~nm}, \sigma_{\mathrm{SP}, \mathrm{TSI}}(\mathrm{cool})$ at $550 \mathrm{~nm}$, (c) $\sigma_{\mathrm{AP}, \mathrm{PSAP}}$ (heated) at $545 \mathrm{~nm}, \sigma_{\mathrm{AP}, \mathrm{AETH}}(\mathrm{cool})$ at $880 \mathrm{~nm}$, and (d) PSAP filter transmittance (Tr)

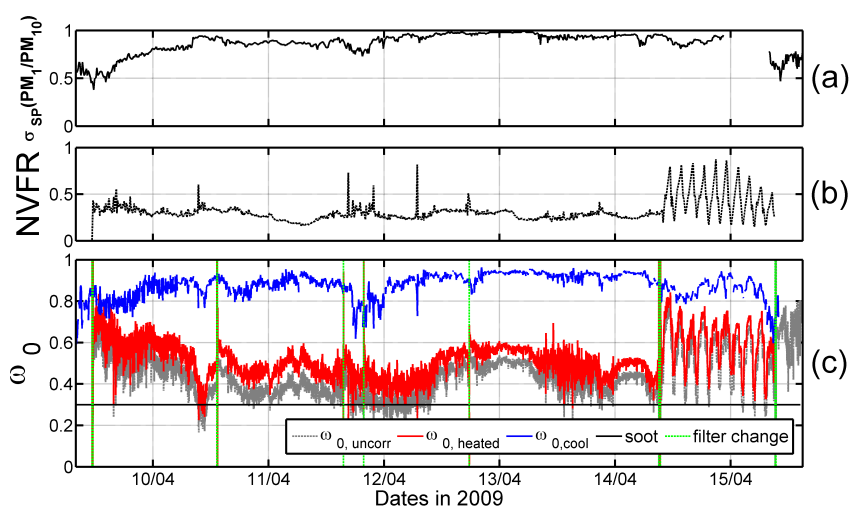

Fig. 4. (a) The contribution by sub-micron particles to total scattering values $\left(\sigma_{\mathrm{SP}}\left(\mathrm{PM}_{1}\right) / \sigma_{\mathrm{SP}}\left(\mathrm{PM}_{10}\right)\right)$ from DMPS and APS data using the refractive index of sulphuric acid $(1.426+0.05 \mathrm{i})$, (b) non-volatile volume fraction remaining (NVFR), and (c) singlescattering albedo $\left(\omega_{0}\right)$ of the heated and the cool urban aerosol calculated at $880 \mathrm{~nm}$ and at $545 \mathrm{~nm}$ respectively. $\omega_{0 \text {, heated }}$ was corrected according to Nakayama et al. (2010) and $\omega_{0}$, uncorr without this correction. The line at $\omega_{0}=0.3$ is the $\omega_{0}$ of laboratory generated pure soot (Mikhailov et al., 2006).

level. However, the $\sigma_{\mathrm{AP}, \mathrm{PSAP}}$ noise decreased to the normal level for long periods even before the following filter change. Humidity generally creates noise in filter-based instruments but after the oven this is for sure not the case.

The time series of the non-volatile volume fraction remaining (NVFR), single-scattering albedo $\left(\omega_{0}\right)$ of the heated 
and cool aerosol $\left(\omega_{0, \text { heated }}\right.$ and $\omega_{0, \text { cool }}$ at $\lambda=545 \mathrm{~nm}$ and $880 \mathrm{~nm}$, respectively) reveal interesting variations (Fig. 4). First of all, approximately $75 \%$ of the aerosol volume had volatilized $(\mathrm{NVFR} \approx 0.25)$ and the difference between the two $\omega_{0}$ 's was $>0.3$, meaning that the residual particles were much darker. This is in agreement with our understanding that in a sub-micron aerosol volatile constituents scatter more light than the non-volatile.

Secondly, in some periods $\omega_{0 \text {, heated }}$ decreased close to 0.3 , the $\omega_{0}$ of soot (e.g., Mikhailov et al., 2006). The noisy periods of $\sigma_{\mathrm{AP}, \mathrm{PSAP}}$ mentioned above occur interestingly simultaneously with clearly elevated and even somewhat noisy NVFR - with the exception of 13 April - and also clearly decreased values of $\omega_{0, \text { cool }}$ suggesting that the noisy $\sigma_{\mathrm{AP}, \mathrm{PSAP}}$ periods may have been due to near-by soot sources such as heavy traffic and vehicles. These noisy periods correlated with wind directions coming from the nearby highway. With heavy traffic and local emissions we would expect a diurnal cycle of dark aerosols at rush hour and less dark aerosol at night time. Since the campaign was conducted mainly over a national holiday there is no clear diurnal cycle even though the above analysis shows that in this period the dark aerosol was mainly observed in the afternoons and evenings.

The third observation from the time series of NVFR and $\omega_{0}$ is that there are periods where the residual aerosol had a different $\omega_{0}$ with roughly the same NVFR. For example $\mathrm{NVFR} \approx 0.25$ and $\omega_{0 \text {, heated }} \approx 0.4$ just after midnight on 12 April. Just after midnight on 13 April NVFR $\approx 0.25$ while $\omega_{0 \text {,heated }} \approx 0.6$. This is most probably an indication of chemically different aerosols entering the oven. Our laboratory tests showed the oven volatilized ammonium sulphate, other typical inorganic sub-micron aerosol constituents are even more volatile (e.g., Engler et al., 2007; Tiitta et al., 2009). We therefore conclude the non-volatile aerosol probably contained organics, in addition to BC. To investigate this further we used back-trajectory analysis and noticed that the clean air with low absorption and scattering coefficients on the 12 April after midnight arrived from the Barents Sea. As the scattering coefficients and $\omega_{0}$ increased later that day the airmass came more and more from continental regions in western Russia. Either the oven was not able to volatilize all of the scattering constituents yielding a higher $\omega_{0}$ or the aerosol contained chemically different more oxidized and less volatile constituents which was not completely removed by the oven.

Another possible reason for the increase of $\omega_{0}$ at about noon of 12 April could be that there were more large, nonvolatile particles. Due to the $\mathrm{PM}_{10}$ inlet to the campaign instruments they were not only measuring sub-micron particles. In these sub-micron particles we expected the light scattering species to be completely or partly evaporated at $280{ }^{\circ} \mathrm{C}$. In the super-micron aerosol we would expect to find crustal material and sea-salt which also scatter light and are not volatile. To assess this influence Aerodynamic Particle Sizer (APS) and DMPS data the fraction of scattering by
$\mathrm{PM}_{1}$ particles to $\mathrm{PM}_{10}$ was calculated with Mie modelling. The scattering coefficient $\sigma_{\mathrm{SP}}$ for $\mathrm{PM}_{1}$ and $\mathrm{PM}_{10}$ particles were calculated from the DMPS and the APS data using

$$
\begin{aligned}
\sigma_{\mathrm{SP}}(\lambda) & =\int Q_{\mathrm{SP}}\left(\lambda, D_{\mathrm{p}, \mathrm{m}}\right) \frac{\pi D_{\mathrm{p}, \mathrm{i}}^{2}}{4} n\left(D_{\mathrm{p}}\right) d D_{\mathrm{p}} \\
& \approx \sum Q_{\mathrm{SP}}\left(\lambda, D_{\mathrm{p}, \mathrm{m}}\right) \frac{\pi D_{\mathrm{p}, \mathrm{i}}^{2}}{4} N_{\mathrm{i}}
\end{aligned}
$$

where $Q_{\mathrm{SP}}\left(\lambda, D_{\mathrm{p}, \mathrm{m}}\right)$ is the scattering efficiency of particles with diameter $D_{\mathrm{p}}$ and the complex refractive index $\mathrm{m}=n_{\mathrm{r}}+n_{\mathrm{i}} i$ at wavelength $\lambda$. The scattering efficiencies were calculated using the Mie code by Barber and Hill (1990). The calculations were done using $\mathrm{m}=1.426+0.05 i$ and $\mathrm{m}=1.526+0.05 i$ for the whole size distribution. The integration was done for the whole size distribution $\left(\sigma_{\mathrm{SP}}\left(\mathrm{PM}_{10}\right)\right)$ and for sub-micron particles $\left(\sigma_{\mathrm{SP}}\left(\mathrm{PM}_{1}\right)\right)$. The ratio $\left(\sigma_{\mathrm{SP}}\left(\mathrm{PM}_{1}\right)\right) / \sigma_{\mathrm{SP}}\left(\mathrm{PM}_{10}\right)$ indicates the contribution of sub-micron particles to scattering (Fig. 4a). This ratio was constantly over 0.8 (and for the most part 0.9) except at the 9 of April and in the afternoon of 15 April. APS data was not available before noon on 15 April.

Instead of decreasing on 12 April the ratio $\left(\sigma_{\mathrm{SP}}\left(\mathrm{PM}_{1}\right)\right) / \sigma_{\mathrm{SP}}\left(\mathrm{PM}_{10}\right)$ was actually increasing (Fig. 4a). If the reason for the increasing $\omega_{0}$ had been the increase of large, non-volatile particles of any kind, this ratio would decrease. Therefore the data rather supports our argumentation above that the increase in $\omega_{0}$ from 0.4 just after midnight on April 12 to 0.6 just after midnight on April 13 with the same NVFR of $\approx 0.25$ possibly is a chemically different aerosol.

In OCEC analysers the sample is heated stepwise, typically to four different temperatures. For instance, the recommended EUSAAR protocol is to heat the sample to 200, 300, 450 , and $650^{\circ} \mathrm{C}$, and in the IMPROVE protocol to 120,250 , 450 , and $550^{\circ} \mathrm{C}$ (Cavalli et al., 2010) yielding concentrations of OC1, OC2, OC3, and OC4 (amount of Organic Carbon volatilized under a certain temperature). In a similar way if there were organics in the volatility ranges OC3 and OC4 present in the aerosol our setup would not have volatilized them. The data suggest this has been the case in the period indicated above. However, we can not prove this for sure since from the whole campaign we only have the total OC data, not different temperature fractions. Another possible explanation would be that in this period the $1.0 \mathrm{~s}$ residence time in the oven was too short to evaporate all organics ( $\mathrm{Ri}$ ipinen et al., 2010).

The residual aerosol is darker than the cool aerosol and therefore there is less scattering aerosol to influence the measurements of light absorption by soot. This generally results in a more accurate measure of MAC (Bond and Bergstrom, 2006). The MAC of EC was determined with linear regression of $\sigma_{\mathrm{AP}}$ from both absorption measurements versus the EC mass concentrations from the OCEC-analyzer. From the aethalometer data $\mathrm{MAC}=6.2 \pm 0.4 \mathrm{~m}^{2} \mathrm{~g}^{-1}$ (Fig. 5a) at $\lambda=880 \mathrm{~nm}$. At $\lambda=545 \mathrm{~nm}$, the MAC calculated from the 
(a)
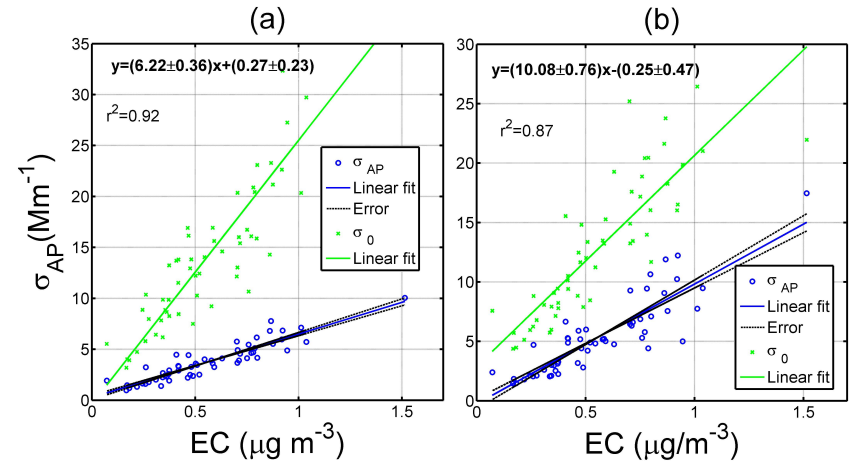

Fig. 5. Mass absorption cross sections (MAC) of soot calculated (a) from aethalometer data at a wavelength of $880 \mathrm{~mm}$ and OCEC data and (b) from PSAP at a wavelength of $545 \mathrm{~nm}$ and OCEC from the slope of the linear regression with Nakayama et al. (2010) size dependent correction factors. The errors were calculated using the standard error for ordinary least square regressions.

heated PSAP data with the Nakayama et al. (2010) correction was $10.1 \pm 0.8 \mathrm{~m}^{2} \mathrm{~g}^{-1}$ (Fig. 5b). When assuming that the wavelength dependency of MAC is $\lambda^{-1}$ both MAC values are in agreement: $\operatorname{MAC}(880 \mathrm{~nm})=10.1(880 / 545)^{-1}=6.3 \mathrm{~m}^{2} \mathrm{~g}^{-1}$.

When the Bond et al. (1999) and Ogren (2010) corrections were used, the MAC was $7.2 \pm 0.4 \mathrm{~m}^{2} \mathrm{~g}^{-1}$. We may argue that the lower MAC obtained by the Bond et al. (1999) method is too low since it is known that at filter transmittances under 0.7 at low $\omega_{0}$ yields too low absorption coefficients.

Without the Nakayama et al. (2010) correction for size dependent filter penetration response the MAC values were $13.5 \pm 0.9 \mathrm{~m}^{2} \mathrm{~g}^{-1}$ and $9.6 \pm 0.5 \mathrm{~m}^{2} \mathrm{~g}^{-1}$ using the Virkkula et al. (2005) and Bond et al. (1999) algorithms respectively. This no longer results in a wavelength dependency of $\lambda^{-1}$ but $\lambda^{-1.62}$ between the MAC's $6.2 \mathrm{~m}^{2} \mathrm{~g}^{-1}(\lambda=880 \mathrm{~nm})$ and $13.5 \mathrm{~m}^{2} \mathrm{~g}^{-1}(\lambda=545 \mathrm{~nm})$.

These results are in agreement with earlier published MAC values $\left(9.1-10.8 \mathrm{~m}^{2} \mathrm{~g}^{-1}\right.$ and $5-25 \mathrm{~m}^{2} \mathrm{~g}^{-1}(\lambda=550 \mathrm{~nm})$, $9.8 \mathrm{~m}^{2} \mathrm{~g}^{-1} \quad(\lambda=565 \mathrm{~nm})$ and $5.9-9.3 \mathrm{~m}^{2} \mathrm{~g}^{-1} \quad(\lambda=880 \mathrm{~nm})$ (e.g., Petzold and Schönlinner, 2004; Snyder and Schauer, 2007; Miyazaki et al., 2008, and references therein).

\subsubsection{Temperature dependence of volatilization}

From 14 April 10:00 to 15 April 09:00 the oven was set to cycle temperatures 50,150 and $280^{\circ}$ for $23 \mathrm{~h}$ and finally the oven was turned off for a few hours. The time series of scattering and aerosol volume concentration show that even the non-heated aerosol did not remain constant during this scanning period, the volume varied about a decade, from about 2 to $20 \mu \mathrm{m}^{3} \mathrm{~cm}^{-3}$ and $\sigma_{\mathrm{SP}, \mathrm{TSI}}$ from about 10 to $100 \mathrm{Mm}^{-1}$ (Fig. 6).

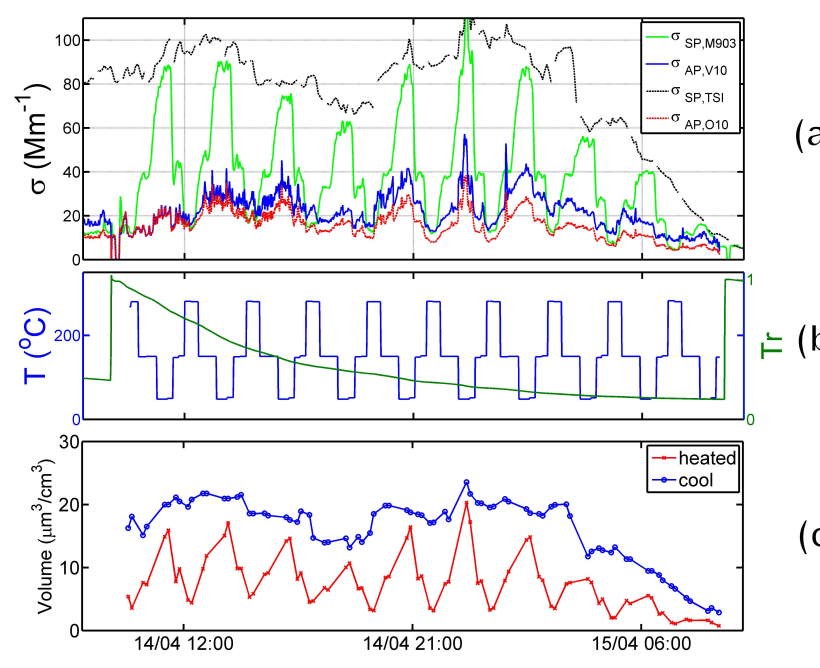

(a)

Fig. 6. (a) Light scattering coefficients $\left(\sigma_{\mathrm{SP}, \mathrm{M} 903}\right.$ (heated) at $\lambda=545 \mathrm{~nm}$ and $\sigma_{\mathrm{SP}, \mathrm{TSI}}(\mathrm{cool})$ at $\left.\lambda=550 \mathrm{~nm}\right)$, light absorption coefficients $\left(\sigma_{\mathrm{AP}, \mathrm{V} 10}\right.$ at $\lambda=545 \mathrm{~nm}$ and $\sigma_{\mathrm{AP}, \mathrm{O} 10}$ at $\left.\lambda=545 \mathrm{~nm}\right)$, (b) oven temperature $(T)$ and PSAP transmittance $(\mathrm{Tr})$, and (c) the volume of the measured aerosol during the temperature scans.

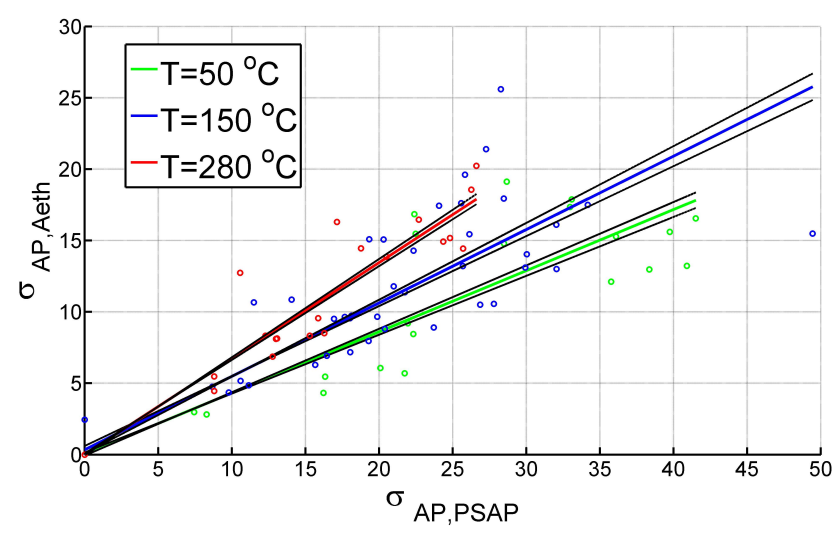

Fig. 7. The temperatures influence on the correlation between the absorption coefficients measurements on the heated aerosol $\left(\sigma_{\mathrm{AP}, \mathrm{PSAP}}\right)$ versus the cool aerosol $\left(\sigma_{\mathrm{AP}, \mathrm{AETH}}\right)$.

Heating made a huge impact on the light scattering properties of the aerosol. The warmer the oven was the more light scattering constituents were evaporated from the aerosol phase. A decrease in $\sigma_{\mathrm{SP}}$ was expected but an interesting observation was that the temperature also influenced $\sigma_{\mathrm{AP}}$. This same issue may be studied by comparing the absorption coefficients of the cool aerosol with the heated one, $\sigma_{\mathrm{AP}, \mathrm{AETH}}$ and $\sigma_{\mathrm{AP}, \mathrm{PSAP}}$, respectively. There are clear differences in the slopes (Fig. 7). One possible explanation is that the scattering correction function by Virkkula et al. (2005) does not compensate for the scattering aerosol deposited on the filter matrix perfectly. 


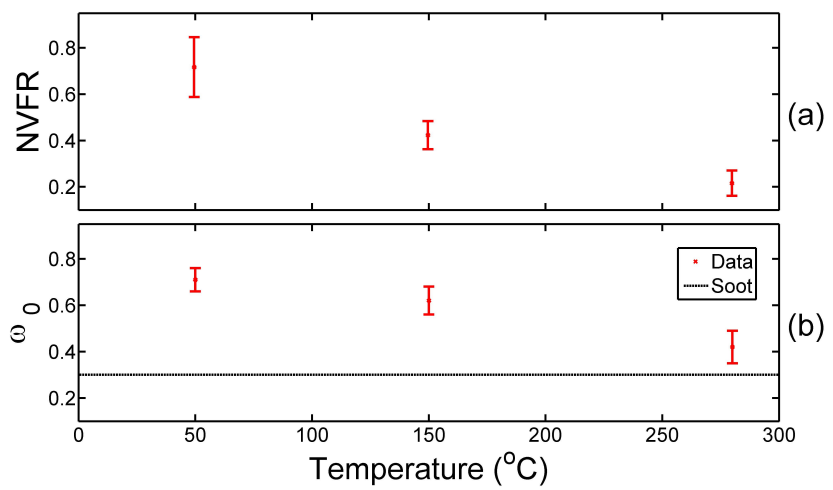

Fig. 8. The amount of (a) particle volume left after heating the aerosol to different temperatures and $(\mathbf{b})$ the influence of temperature the aerosol was heated to in respect to the single-scattering albedo $\left(\omega_{0}\right)$ of the aerosol measured between 14 April 2009 LT 10:00 and 15 April 2009 LT 09:00.

Since the amount of residual scattering aerosol is a function of temperature and light scattering is a variable in the correction function to calculate the absorption the variations in scattering do influence the results. However, a more likely explanation is that the mixing state of the aerosol changes during heating and therefore changes the absorption properties of the aerosols. It has been shown that the mixing state of soot in an aerosol can increase the amount of radiation the aerosol absorbs (Fuller et al., 1999). The fact that the volatilisation of light scattering matter from the aerosol can influence the light absorption coefficient is a possible indication of internally mixed soot. Soot is externally mixed immediately after emission but gets coated with non-absorbing constituents during transport in the atmosphere. The longer soot has aged the more likely it is that it gets internally mixed with light scattering constituents (Saathoff et al., 2003; Zhang et al., 2008).

By analysing the temperature scan data we got NVFR of $0.72 \pm 0.13,0.42 \pm 0.06$, and $0.22 \pm 0.05$ for 50,150 , and

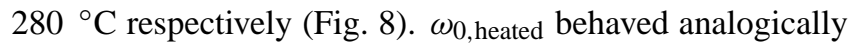
and was $0.71 \pm 0.05,0.62 \pm 0.06$, and $0.42 \pm 0.07$ at the respective temperatures. At $280^{\circ} \mathrm{C}$ the non-volatile particles had almost reached the $\omega_{0}$ of soot $(\approx 0.3)$ in some of the scans but in most clearly higher, about 0.4 and higher, indicating again possible non-volatile organics, too short residence time or to low temperature. The analogical behaviour of NVFR and $\omega_{0 \text {,heated }}$ raises the question of the type of relationship they have. There was a clear decreasing trend in $\omega_{0, \text { heated }}$ as a function of NVFR but it was not quite linear: the $\omega_{0}$ drop was approximately as large when NVFR dropped from 0.4 to 0.3 as when it dropped from 0.8 to 0.4 (Fig. 9). The reason for this may be the effect of scattering layers around the absorbing core.

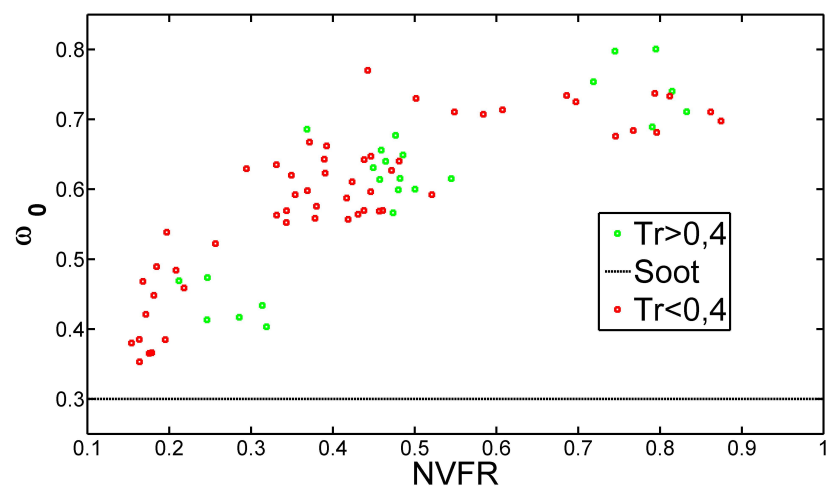

Fig. 9. The relationship between non-volatile volume fraction remaining (NVFR) and single-scattering albedo $\left(\omega_{0}\right)$. The measurements were done on the 14 April LT 10:00 to 15 April LT 09:00.

For those data where $\omega_{0}<0.4$ NVFR was $\approx 0.2$ and is slightly higher than the published volume fractions of $\mathrm{BC}$ in $\mathrm{PM}_{2.5}$ (Viidanoja et al., 2002; Putaud et al., 2004). This is what we would expect since the non-volatile soot particles are found well beneath the cut off size of $\mathrm{PM}_{2.5}$ (Philippin et al., 2004; Engler et al., 2007). Most traffic-related less volatile particles have been shown to be between 80 and $150 \mathrm{~nm}$ (Wehner et al., 2004).

We can still get another piece of information out of the

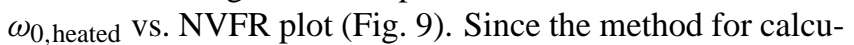
lating $\sigma_{\mathrm{AP}}$ was only calibrated for filter transmittances $>0.4$ (Virkkula, 2010) the respective data were plotted in green in Fig. 9. The fact that there is no obvious difference between values obtained with $\operatorname{Tr}<0.4$ and $\operatorname{Tr}>0.4$ indicates that the used method seems to be suitable for even lower transmittances than indicated in the original paper.

\section{Conclusions}

We measured the effect of heating on light scattering and absorption by aerosols at an urban background station in Helsinki from 9 to 15 April 2009. First the heating temperature was kept constant at $280^{\circ} \mathrm{C}$ for five days and then temperatures 50,150 , and $280^{\circ} \mathrm{C}$ were scanned for $23 \mathrm{~h}$. Heating significantly altered the optical and physical properties of the particles. The scattering constituents got volatilised resulting in a darker aerosol. The single-scattering albedo of the residual aerosol $\left(\omega_{0}\right.$,heated $)$, as well as the non-volatile volume fraction remaining (NVFR), decreased almost linearly as a function of the heating temperature.

Heating the aerosol will volatilize light scattering constituents which are responsible for increasing light absorption by the aerosol due to different mixing states of soot. Without volatilisation this will lead to over prediction of BC mass concentrations since internally mixed soot absorbs more light than externally mixed soot. 
Light attenuation by light scattering aerosol particles deposited on the filter get interpreted as light absorption, if not taken into account. There are correction algorithms for compensating for this apparent absorption. Volatilisation will reduce the apparent absorption and the correction algorithms influence on the result. This is the case for any filter-based absorption measurement instrument even after a volatilisation oven. However, the result of this study suggests that it is not necessarily as simple as just removing all scattering material and then getting a non-biased $\sigma_{\mathrm{AP}}$.

Volatilisation shrinks the size of the particles which penetrate deeper into the filter-matrix. This increases the filterbased instrument's response to light absorption by particles due to multiple scattering by the filter matrix and needs to be corrected for. When corrected for, absorption by soot can be measured with a greater accuracy to assess the mass concentration of BC in the sample air.

The fact that there seems to be a temperature dependence of the calculated absorption coefficients is probably an indication of different mixing states of the aerosol achieved by partial, complete or no volatilisation in the oven. Different mixing states of soot have been shown to affect light absorption so that internally mixed soot in an aerosol absorbs more light than externally mixed soot (Fuller et al., 1999).

Fractal like soot particles collapse to globules during cloud processing (Mikhailov et al., 2006). A change from a collapsed soot core to a fractal like structure in the thermodenuder would cause an artefact (Fuller et al., 1999). In this study we can only assume the geometry of the soot core does not change in the volatilisation oven since no microscopic pictures of the residual particles were taken.

Using the parametrisation by Nakayama et al. (2010) the mass absorption cross section of the heated aerosol was calculated to be $10.1 \pm 0.8 \mathrm{~m}^{2} \mathrm{~g}^{-1}$ at $\lambda=545 \mathrm{~nm}$ with the PSAP algorithm presented by Virkkula et al. (2005); Virkkula (2010) and $7.2 \pm 0.4 \mathrm{~m}^{2} \mathrm{~g}^{-1}$ with the Bond et al. (1999) correction with the modification by Ogren (2010) and the OCEC data. These values are roughly $75 \%$ less than they would have been without compensating for the increased penetration depth due to volatilisation of light scattering constituents. On average the absorption measurements were divided with a correction factor $F_{\mathrm{D}}$ of 1.43 . For the nonheated aerosol MAC $=6.2 \pm 0.4 \mathrm{~m}^{2} \mathrm{~g}^{-1}$ was calculated from aethalometer data at $\lambda=880 \mathrm{~nm}$. These values are consistent with published values but our data leaves a question open: is this difference in MAC calculated from the two instruments due to wavelength only or is it due to different states of mixing. This should be studied by making both heated and non-heated measurements at equal wavelengths and similar instruments.

An interesting observation is that there were periods where

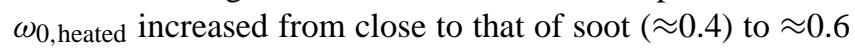
even though the NVFR remained at about 0.25 and the oven was kept at the constant temperature of $280^{\circ} \mathrm{C}$. A probable explanation to this is that in these periods in the parti- cles there was organic carbon that volatilizes only at higher temperatures, since the typical inorganic sub-micron species get volatilized at this temperature. In the standard thermaloptical OCEC analysis there are four temperature steps, two of them yield concentrations of OC that volatilize at temperatures $>300^{\circ} \mathrm{C}$ (Cavalli et al., 2010). The measurement of $\omega_{0 \text {, heated }}$ and NVFR could possibly be used as an indication of the presence of these organics. How quantitative this would be remains to be studied.

As the PSAP filter gets darker the difference in the absorption coefficients calculated with the logarithmic loading correction function (Virkkula et al., 2005; Virkkula, 2010) and the more commonly used Bond et al. (1999) correction becomes significant. The comparison of the non-volatile volume fraction and single-scattering albedo during the heating temperature cycling period suggests that the logarithmic loading correction function works even at transmittances lower than 0.4 .

Acknowledgements. We acknowledge the financial support by the Maj and Tor Nessling foundation under grant 2008400 and 2009399 and the technical assistance of Timo Mäkelä.

Edited by: A. Wiedensohler

\section{References}

Aalto, P., Hämeri, K., Becker, E., Weber, R., Salm, J., Mäkelä, J., Hoell, C., O’Dowd, C., Karlsson, H., Hansson, H.-C., Väkevä, M., Koponen, I., Buzorius, G., and Kulmala, M.: Physical characterization of aerosol particles during nucleation events., Tellus, 53B, 344-358, 2001.

An, W. J., Pathak, R., Lee, B.-H., and Pandis, S.: Aerosol volatility measurement using an improved thermodenuder: Application to secondary organic aerosol, J. Aerosol Sci., 38, 305-314, 2007.

Anderson, T., Covert, D., Marshall, S., Laucks, M., Charlson, R., Waggoner, A., Ogren, J., Caldow, R., Holm, R., Quant, F., Sem, G., Wiedensohler, A., Ahlquist, N., and Bates, T.: Performance characteristics of a high-sensitivity, three-wavelength, total scatter/backscatter nephelometer, J. Atmos. Ocean. Tech., 13, 967985, 1996.

Arnott, W., Hamasha, K., Moosmüller, H., Sheridan, P., and Ogren, J.: Towards aerosol light-absorption measurements with a 7wavelength aethalometer: evaluating with a photoacoustic instrument and 3-wavelength nephelometer, Aerosol Sci. Tech., 39, 17-29, 2005.

Backman, J.: Aerosolpartiklars flyktighet och deras optiska egenskaper, Master's thesis, University of Helsinki, Helsinki, 2009.

Barber, P. and Hill, S.: Light Scattering by Particles: Computational Methods, World Scientific Pub Co Inc, 1990.

Birch, M. and Cary, R.: Elemental Carbon-Based Method for Monitoring Occupational Exposures to Particulate Diesel Exhaust, Aerosol Sci. Tech., 25, 221-241, 1996.

Bond, T. and Bergstrom, R.: Light Absorption by Carbonaceous Particles: An Investigative Review, Aerosol Sci. Tech., 40, 2767, 2006. 
Bond, T., Anderson, T., and Campbell, D.: Calibration and Intercomparison of Filter-Based Measurements of Visible Light Absorption by Aerosols, Aerosol Sci. Tech., 30, 582-600, 1999.

Cabada, J., Khlystov, A., Wittig, A., Pilinis, C., and Pandis, S.: Light Scattering by fine particles during the Pittsburg Air Quality Study: Measurements and modeling, J. Geophys. Res., 109, D16S03, doi:10.1029/2003JD004155, 2004.

Cavalli, F., Viana, M., Yttri, K. E., Genberg, J., and Putaud, J.P.: Toward a standardised thermal-optical protocol for measuring atmospheric organic and elemental carbon: the EUSAAR protocol, Atmos. Meas. Tech., 3, 79-89, doi:10.5194/amt-3-79-2010, 2010.

Engler, C., Rose, D., Wehner, B., Wiedensohler, A., Brüggemann, E., Gnauk, T., Spindler, G., Tuch, T., and Birmili, W.: Size distributions of non-volatile particle residuals $\left(\mathrm{D}_{p}<800 \mathrm{~nm}\right)$ at a rural site in Germany and relation to air mass origin, Atmos. Chem. Phys., 7, 5785-5802, doi:10.5194/acp-7-5785-2007, 2007.

Fuller, K., Malm, W., and Kreidenweis, S.: Effects of mixing on extinction by carbonaceous particles, J. Geophys. Res., 104(D13), 941-954, doi:10.1029/1998JD100069, 1999.

Hansen, A., Rosen, H., and Novakov, T.: The Aethalometer-An instrument for the real-time measurement of optical absorption by aerosol particles, Sci. Total Environ., 36, 191-196, 1984.

Heintzenberg, J., Wiedensohler, A., Tuch, T., Covert, D., Sheridan, P., Ogren, J., Gras, J., Nessler, R., Kleefeld, C., Kalivitis, N., Aaltonen, V., Wilhelm, R.-T., and Havlicek, M.: Intercomparisons and Aerosol Calibrations of 12 Commercial Integrating Nephelometers of Three Manufacturers, J. Atmos. Ocean. Tech., 23, 902-914, 2006.

Hoppel, W.: Determination of the aerosol size distribution from the mobility distribution of the charged fraction of aerosols, J. Aerosol Sci., 9, 41-54, doi:10.1016/0021-8502(78)90062-9, 1978.

Jacobson, M.: Strong radiative heating due to the mixing state of black carbon in atmospheric aerosols, Nature, 409, 695-697, 2001

Järvi, L., Hannuniemi, H., Hussein, T., Junninen, H., Aalto, P., Hillamo, R., Mäkelä, T., Keronen, P., Siivola, E., Vesala, T., and Kulmala, M.: The urban measurement station SMEAR III: Continuous monitoring of air pollution and surface-atmosphere interactions in Helsinki, Finland, Boreal Env. Res., 14, 86-109, 2009.

Jokinen, V.: Aerosolihiukkasten ja ilman ionien mittaus differentiaalisella liikkuvuusanalysaattorilla, Report Series in Aerosol Science, 1995.

Liu, L.-J. S., Slaughter, J., and Larson, T.: Comparison of Light Scattering Devices and Impactors for Particulate Measurements in Indoor, Outdoor, and Personal Environments, Environ. Sci. Technol., 36, 2977-2986, 2002.

Mertes, S., Schröder, F., and Wiedensohler, A.: The particle detection efficiency curve of the TSI-3010 CPC as a function of the temperature difference between saturator and condenser, Aerosol Sci. Tech., 23, 257-261, 1995.

Mikhailov, E., Vlasenko, S., Podgorny, I., Ramanathan, V., and Corrigan, C.: Optical properties of soot-water drop agglomerates: An experimental study, J. Geophys. Res., 111, 1-16, 2006.

Miyazaki, Y., Kondo, Y., Sahu, L., Imaru, J., Fukushima, N., and Kanod, M.: Performance of a newly designed continuous soot monitoring system (COSMOS), J. Environ. Monitor., 10, 11951201,2008
Moteki, N., Kondo, Y., Nakayama, T., Kita, K., Sahu, L., Ishigai, T., Kinase, T., and Matsumi, Y.: Radiative transfer modeling of filter-based measurements of light absorption by particles: Importance of particle size dependent penetration depth, J. Aerosol Sci., 41, 401-412, doi:10.1016/j.jaerosci.2010.01.004, 2010.

Nakayama, T., Kondo, Y., Moteki, N., Sahu L., Kinase, T., Kita, K., and Matsumi, Y.: Size-dependent correction factors for absorption measurements using filter-based photometers: PSAP and COSMOS, J. Aerosol Sci., 41, 333-343, doi:10.1016/j.jaerosci. 2010.01.004, 2010.

Ogren, J.: Comment on Calibration and Intercomparison of FilterBased Measurements of Visible Light Absorption by Aerosols, Aerosol Sci. Tech., in print, 2010.

VanOsdell, D., Liu, B., Rubow, K. and Pui, D.: Experimental Study of Submicrometer and Ultrafine Particle Penetration and Pressure Drop for High Efficiency Filters, Aerosol Sci. Tech., 12(4), 911 925, doi:10.1080/02786829008959403, 1990.

Petzold, A. and Schönlinner, M.: Multi-angle absorption photometry - a new method for measurement of aerosol light absorption and atmospheric black carbon, J. Aerosol Sci., 35, 421-441, 2004.

Philippin, S., Wiedensohler, A., and Stratmann, F.: Measurements of non-volatile fractions of pollution aerosols with an eight-tube volatility tandem differential mobility analyzer (VTDMA-8), J. Aerosol Sci., 35, 185-203, 2004.

Putaud, J.-P., Raes, F., Dingenen, R., Brüggemann, E., Facchini, M.-C., Decesari, S., Fuzzi, S., Gehrig, R., Hüglin, C., Laj, P., Lorbeer, G., Maenhaut, W., Mihalopoulos, N., Müller, K., Querol, X., Rodriguez, S., Schneider, J., Spindler, G., ten Brink, H., Torseth, K., and Wiedensohler, A.: A European aerosol phenomenology-2:chemical characteristics of particulate matter at kerbside, urban, rural and background sites in Europe, Atmos. Environ., 38, 2579-2595, 2004.

Ramanathan, V. and Carmichael, G.: Global and regional changes due to black carbon, Nat. Geosci., 1, 221-227, doi:10.1038/ ngeo156, 2008.

Ramanathan, V., Crutzen, P. J., Kiehl, J. T., and Rosenfeld, D.: Aerosols, Climate, and the Hydrological Cycle, Science, 294, 2119-2124, doi:10.1126/science.1064034, 2001.

Riipinen, I., Pierce, J., Donahue, N., and Pandis, S.: Equilibration time scales of organic aerosol inside thermodenuders: Evaporation kinetics versus thermodynamics, Atmos. Environ., 44, 597607, 2010.

Rosenfeld, D., Lohmann, U., Raga, G. B., O’Dowd, C. D., Kulmala, M., Fuzzi, S., Reissell, A., and Andreae, M.: Flood or Drought: How Do Aerosols Affect Precipitation?, Science, 321, 1309-1313, doi:10.1126/science.1160606, 2008.

Saathoff, H., Naumanna, K.-H., Schnaitera, M., Schöcka, W., Móhler, O., Schuratha, U., Weingartnerb, E., Gyselb, M., and Baltensperger, U.: Coating of soot and $\left(\mathrm{NH}_{4}\right)_{2} \mathrm{SO}_{4}$ particles by ozonolysis products of $\alpha$-pinene, J. Aerosol Sci., 34, 1297-1321, 2003.

Seinfeld, J. and Pandis, S.: Atmospheric Chemistry and Physics From airpollution to climate change, Wiley-Interscience, 2006.

Slowik, J., Cross, E., Han, J., Kolucki, J., Davidovits, P., and Williams, L.: Measurements of Morphology Changes of Fractal Soot Particles using Coating and Denuding Experiments: Implications for Optical Absorption and Atmospheric Lifetime, Aerosol Sci. Tech, 41(8), 734-750, doi:10.1080/ 
$02786820701432632,2007$.

Snyder, D. and Schauer, J.: An Inter-Comparison of Two Black Carbon Aerosol Instruments and a Semi-Continuous Elemental Carbon Instrument in the Urban Environment, Aerosol Sci. Tech., 41, 463-474, 2007.

Springston, S. and Sedlacek, A.: Noise Characteristics of an Instrumental Particle Absorption Technique, Aerosol Sci. Tech., 41, 1110-1116, 2007.

Stolzenburg, M. and McMurry, P.: An Ultrafine Aerosol Condensation Nucleus Counter, Aerosol Sci. Tech., 14, 48-65, 1991.

Tiitta, P., Miettinen, P., Vaattovaara, P., Joutsensaari, J., Petäjä, T., Virtanen, A., Raatikainen, T., Aalto, P., Portin, H., Romakkaniemi, S., Kokkola, H., Lehtinen, K., Kulmala, M., and Laaksonen, A.: Roadside aerosol study using hygroscopic, organic and volatility TDMAs: Characterization and mixing state, Atmos. Environ., 44, 1-11, 2009.

Viidanoja, J., Sillanpää, M., Laakia, J., Kerminen, V.-M., Hillamo, R., Aarnio, P., and Koskentalo, T.: Organic and black carbon in PM2.5 and PM10: 1 year of data from an urban site in Helsinki, Finland, Atmos. Environ., 36, 3183-3193, 2002.

Virkkula, A.: Correction of the calibration of the 3-wavelength Par-

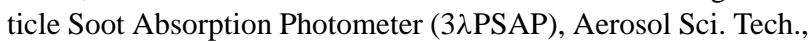
in print, 12, 2010.

Virkkula, A., Ahlquist, N., Covert, D., Arnott, W., Sheridan, P., Quinn, P., and Coffman, D.: Modification, Calibration and Field Test of an Instrument for Measuring Light Absorption by Particles, Aerosol Sci. Tech., 39, 68-83, 2005.
Wehner, B., Philippin, S., and Wiedensohler, A.: Design and calibration of a thermodenuder with an improved heating unit to measure the size-dependent volatile fraction of aerosol particles, J. Aerosol Sci., 33, 1087-1093, 2002.

Wehner, B., Philippin, S., Wiedensohler, A., Scheer, V., and Vogt, R.: Variability of non-volatile fractions of atmospheric aerosol particles with traffic influence, Atmos. Environ., 38, 6081-6090, 2004.

Wehner, B., Petäjä, T., Boy, M., Engler, C., Birmili, W., Tuch, T., Wiedensohler, A., and Kulmala, M.: The contribution of sulfuric acid and non-volatile compounds on the growth of freshly formed atmospheric aerosols, Geophys. Res. Lett., 32, L17810, doi:10.1029/2005GL023827, 2005.

Weingartner, E., Saathoff, H., Schnaiter, M., Streit, N., Bitnar, B., and Baltensperger, U.: Absorption of light by soot particles: determination of the absorption coeffcient by means of aethalometers, J. Aerosol Sci., 34, 1445-1463, 2003.

Winklmayr, W., Reischl, G., Lindner, A., and Berner, A.: A new electromobility spectrometer for the measurement of aerosol size distributions in the size range of 1 to $1000 \mathrm{~nm}$, J. Aerosol Sci., 22, 289-296, 1991.

Zhang, R., Khalizov, A. F., Pagels, J., Zhang, D., Xue, H., and McMurry, P.: Variability in morphology, hygroscopicity, and optical properties of soot aerosols during atmospheric processing, P. Natl. A. Sci., 105, 10291-10296, 2008. 